\title{
The long-term complications of hyperglycemia in both typel and type 2 diabetic patients
}

\begin{abstract}
Diabetes mellitus is a common chronic disease that spread worldwide. Hyperglycemia with combinations of other factors causes many changes in the body which lead to serious complications. Fortunately, most of the risk factors can be modified with control glucose level and a healthy life style, both of them is crucial to reducing complications, morbidity, and mortality. This article illustrates the hyperglycemia damage mechanism and the prevalence of most common diabetic complication.
\end{abstract}

Keywords: diabetes mellitus, diabetic complication, hyperglycemia, risk factors
Volume 7 Issue 5 - 2018

\author{
Alaa A Elnour \\ Department of Medical Lab Science, National Ribat University, \\ Saudi Arabia \\ Correspondence: Alaa A Elnour, Department of Medical Lab \\ Science, National Ribat University, Saudi Arabia, \\ Email alaa.a.elnour@outlook.com
}

Received: August 0I, 20I8 | Published: September 06, 2018

\section{Introduction}

The prevalence of diabetes has increased rapidly over the past several decades, the number has risen from 108million in 1980 to 422million in 2014. ${ }^{1}$ Increasing urbanization, aging populations, obesity, and falling levels of physical activity are all contributing to increase in diabetes worldwide. ${ }^{2}$

\section{Diabetes complications}

A number of changes occur in the body because of diabetes: metabolism and blood circulation changes. Uncontrolled diabetes leads to serious complications, especially the nerves and blood vessels, which is a major cause of stroke, lower limb amputation, blindness, kidney failure and heart attacks. The complication includes micro vascular complications, macro vascular complications, and other miscellaneous complications. ${ }^{3}$ Hyperglycemia leads to formation of advanced glycation end products causing hyper filtration and renal injury, oxidative stress, and activation of cytokines (low-grade inflammation $),{ }^{4}$ that induces changes in the micro vascular, these changes and other factors may lead to macro vascular complications. ${ }^{5}$ Micro vascular complications are retinopathy, nephropathy, and neuropathy; and macro vascular complications cause by atherothrombotic, atherosclerosis is more common in diabetes patients which increase the risk of stroke in people more than 5times than in those without DM. ${ }^{6,7}$ Studies show that there is a pathological interaction between micro vascular and macro vascular complications in diabetes. Nevertheless, they have a different structure and function. Macro vessels supplying blood to organs, and micro vessels play important roles in maintaining blood pressure and proper nutrient delivery. ${ }^{8}$ The odds of diabetes complications increase for every year of diabetes duration especially the micro vascular complications. ${ }^{9}$ Study hold in United Kingdom shows that at diagnosis of diabetes, $7.3 \%$ of patients had microalbuminuric, worse rising to $17.3 \%$ after 5 years, $24.9 \%$ after 10 years and $28.0 \%$ after 15 years. ${ }^{10}$

Microalbuminuria is urinary albumin (protein) excretion is an earlier sign of vascular damage in both the kidney and the heart, it serves as a marker. ${ }^{11}$ In type $1 \mathrm{DM}$ the prevalence of proteinuria is $15-40 \%$, while in type 2DM range between 5-20\%. ${ }^{12}$ The metabolic and hormonal changes because of hyperglycemia destroy the kidneys and increasing protein passage through the glomerular filtration barrier. Albuminuria in many cases considered the first sign of kidney disease. The combination of genetic risk with inflammation, endothelial dysfunction and hyperglycemia leads to microalbuminuria and, eventually, diabetic nephropathy. ${ }^{13}$ Diabetic nephropathy is the result of the action and interaction of numerous metabolic and hemodynamic factors on the kidney. ${ }^{14}$ Diabetes mellitus type 1 and type 2 patients with longer duration of diabetes, Dyslipidemia, Obesity, hyperglycemia, Smoking, advanced age, and gender; have a higher risk for developing nephropathy ${ }^{15}$ The prevalence of diabetic kidney disease was increased from $7.1 \%$ in $1988-1994$ to $8.6 \%$ in $1999-2004$ and $10.7 \%$ in $2005-2008$. Studies show that more than $40 \%$ of people with diabetes will develop chronic kidney disease. ${ }^{16}$ Approximately $5-15 \%$ of patients with type 2 diabetes and $40 \%$ of patients with type 1 diabetes will develop end-stage renal disease ESRD. ${ }^{17}$ Fortunately, most of these risk factors can modifiable, clinical trials demonstrated that strict glycemic control reduces the risk of progression severe albuminuria and other diabetes micro vascular complications. ${ }^{18}$

\section{Summary}

There are numerous risk factors for diabetic nephropathy, most of them related to lifestyle and genetic factor. According to different studies, the risk of the diabetic patient to develop the complication increasing yearly is not preventable but can be reduced. People with long diabetic duration have a higher risk of developing complications. The main question here, with control glucose level and good lifestyle how to prevent these complications?

\section{Acknowledgments}

None.

\section{Conflict of interests}

The author declares that there is no conflict of interest.

\section{References}

1. Mathers CD, Loncar D. Projections of global mortality and burden of disease from 2002 to 2030. PLoS Med. 2006,3(11):442.

2. Michael J, Fowler. Diabetes: Magnitude and Mechanisms. Clinical Diabetes. 2007;28(1):42-46.

3. Nikolaos Papanas, Maciej Banach, Dimitrios Papazoglou, et al. Complications of Diabetes 2016. Konstantinos Papatheodorou. $J$ Diabetes Res; 2016.

4. Vecihi Batuman. Diabetic Nephropathy. Medscape; 2018. 
5. Aastha Chawla, Rajeev Chawla, Shalini Jaggi. Indian Microvasular and macrovascular complications in diabetes mellitus: Distinct or continuum? J Endocrinol Metab. 2016;20(4):546-551.

6. Krentz AJ, Clough G, Byrne CD. Interactions between microvascular and macrovascular disease in diabetes: pathophysiology and therapeutic implications. Diabetes Obes Metab. 2007;9(6):781-791.

7. Khoury JC, Kleindorfer D, Alwell K, et al. Diabetes mellitus: a risk factor for ischemic stroke in a large biracial population. Epub. 2013;44(6):1500-1504.

8. Orasanu G, Plutzky J. The pathologic continuum of diabetic vascular disease. J Am Coll Cardiol. 2009;53(5 Suppl):35-42.

9. Gerstein HC, Mann JF, Pogue J, et al. Prevalence and determinants of microalbuminuria in high-risk diabetic and nondiabetic patients in the Heart Outcomes Prevention Evaluation Study. The HOPE Study Investigators. Diabetes Care. 2000;23(2):35-39.

10. Amanda I, Adler Richard J, Stevens Sue E, et al. Development and progression of nephropathy in type 2 diabetes: The United Kingdom Prospective Diabetes Study (UKPDS 64). Kidney Int. 2003,63(1):225-232.

11. Koroshi A. Microalbuminuria, is it so important? Hippokratia. 2007;11(3):105-107.
12. Azevedo MJ, Silveiro SP, Canani LH, et al. Diabetic nephropathy: diagnosis, prevention, and treatment. Diabetes Care. 2005;28(1):164-176.

13. Aastha Chawla, Rajeev Chawla, Shalini Jaggi. Microvasular and macrovascular complications in diabetes mellitus: Distinct or continuum? Indian J Endocrinol Metab. 2016;20(4):546-551.

14. Moța1 E, Panduru MN, simona G, et al. Risk Factors for Diabetic Nephropathy: Intrinsic or Extrinsic Renal? Rom J Intern Med. 2009;47(4):397-401.

15. Athyros, Konstantinos Tziomalos, Vasilios G. Diabetic Nephropathy: New Risk Factors and Improvements in Diagnosis. Rev Diabet Stud. 2015;12(2):110-118.

16. Osama Gheith, Nashwa Farouk, Narayanan Nampoory, et al. Diabetic kidney disease: worldwide difference of prevalence and risk factors. $J$ Nephropharmacol. 2016;5(1):49-56.

17. Timothy C, Evans, Peter Capell. Diabetic Nephropathy. Clinical Diabetes. 2000;1-18.

18. Boer IH, Afkarian M, Rue TC, et al. Renal outcomes in patients with type 1 diabetes and macroalbuminuria. J Am Soc Nephrol. 2014;25(10):2342-2350. 